\section{Journal of Scientific Instruments}

A Monthly Publication dealing with the Principles, Construction and use of Scientific Instruments. Edited by Dr. H. R. Lang. Vol. 30, 1953. Pp. vii + 502. (London: Institute of Physics, 1953.) £5 11s.

7 HE Journal of Scientific Instruments, the older of the two monthly publications of the Institute of Physies, is devoted to the principles, construction and use of scientific instruments and is edited by Dr. H. R. Lang, secretary of the Institute. Vol. 30, which covers 1953, is considerably larger than its predecessor and contains three special articles, 129 original contributions, sixty-three laboratory and workshop notes, reviews and notices of new books and descriptions of new instruments, materials and tools. The number of items published under the last-named heading is sixty, compared with thirtyeight in Vol. 29, but the number of notices of manufacturers' publications is reduced to twenty and has apparently ceased to be a regular feature. Not only the standard of the contributions but also the quality of their publication are fully in accord with the general high level that the Institute maintains, the graphs and diagrams being particularly clear.

A glance at the comprehensive subject index shows that almost every branch of physics is represented and that many new instruments suitable for use in physical, medical, engineering and other scientific investigations are described. The authors are drawn mainly from the staffs of university and government research laboratories both in Great Britain and abroad, but several are from industrial organizations. The items of more general interest are a preview of the 1953 British Instrument Industries Exhibition; a description of the 1953 Physical Society's exhibition of scientific instruments; a special article by J. R. Scott, of the Research Association of British Rubber Manufacturers, dealing with instruments for measuring plasticity in the rubber industry; and the text of the lecture delivered by A. C. G. Menzies at the Bournemouth convention of the Institute on May 28, 1953, in which recent developments in applied optics are interestingly described and illustrated.

\section{Flowers of the South}

Native and Exotic. By Wilhelmina F. Greene and Hugo L. Blomquist. Pp. $x v+208+27$ plates. (Chapel Hill, N.C.: University of North Carolina Press: London: Oxford University Press, 1953.) 40s. net.

THIS account of some of the flowers of the southern States of the United States is intended not for the technical botanist but for the general reader. In pursuit of this objective the text, for which Dr. H. L. Blomquist, head of the Department of Botany in Duke University, has been mainly responsible, is written around the series of illustrations, mostly the work of Mrs. Greene. These illustrations comprise three categories. The first consists of attractive black-and-white drawings featuring more than five hundred and thirty different species, of which the majority are wild flowers and less than a hundred exotics. Most of these are excellent portrayals of their subjects, sufficiently large and detailed to permit of easy recognition. The second category comprises forty coloured illustrations of individual species, while the third consists of fifteen groups in colour, which are the least successful because so many flowers are here associated that individually they are not infrequently too small, and the effect is rather confused; but some of the three hundred flowers in these groups portray in colour species shown more clearly in black-and-white.

The textual accompaniment varies appreciably in character but usually provides data as to habitat, sometimes details which will assist in identification and often information of a miscellaneous character.

This book is, in fact, primarily an annotated picture-gallery of flowers, and many will be glad to possess it for the illustrations alone.

\section{E. J. SALISBURY}

\section{The Essentials of Physics}

By D. R. J. Wood. Pp. xiv +322 . (London : J. M. Dent and Sons, Ltd., 1954.) 168.

T $N$ this book the author has attempted to give a summary of all branches of physics necessary for the advanced and scholarship levels of the General Certificate of Education, a knowledge up to ordinary level being assumed, and he has done a good job. For the student who has followed a systematic course, the book will certainly serve as a useful revision course for memorizing formulæ and learning what the author calls the essentials. One hopes, however, that the book will not fall into the inexperienced hands of any casual student who sees in it a possible short cut to examination success; it may not turn out this way, and certainly the author does not intend the book to be so used.

A lot of the revision is in mathematical form; there are no lengthy descriptions and the author has not wasted any words. Of necessity, a great deal of the work is incomplete, but what has been attempted (one might say the barest essentials) has been done well.

One final suggestion. It might be advisable in a future issue to use the term supersonics for speeds greater than sound and ultrasonics for frequencies beyond the limit of audibility; this would conform to current practice.

T. M. YARWOOD

Sound

A Physical Text-book. By Dr. E. G. Richardson. Fifth edition. Pp. vii +352. (London: Edward Arnold and Co., 1953.) 25s. net.

LL students of physics will assuredly give a hearty welcome to yet another edition of this very well-known, excellent and authoritative book on sound. Since the first edition was published in 1927 much attention has rightly been focused on this hitherto neglected subject, and through the years Dr. Richardson himself has made notable contributions to its advancement.

The book covers all that a candidate for the pass and honours examinations of British and American universities should require, but the author has not forgotten the needs of those research workers and technicians who are not primarily concerned with examinations. Accordingly, several chapters are included to suit their specialized requirements.

A knowledge of physics and mathematics to firstyear university standard and of calculus is assumed, and the mathematical theory given is easy to follow and quite sufficient to enable physical conceptions to be followed.

In this edition a considerable rearrangement of the text is made and a certain amount of new material is added. In addition, copious references are grouped together at the ends of the chapters, and these should be helpful to those who wish to delve more deeply into any topic in which they are particularly interested. 